\title{
Genetically Modified Rabbits for Cardiovascular Research
}

\author{
Jianglin Fan ${ }^{1,2,3 *}$, Yanli Wang ${ }^{1}$ and Y. Eugene Chen ${ }^{4}$ \\ ${ }^{1}$ Department of Pathology, Xi'an Medical University, Xi'an, China, ${ }^{2}$ Department of Molecular Pathology, Faculty of Medicine, \\ Graduate School of Interdisciplinary Research, University of Yamanashi, Yamanashi, Japan, ${ }^{3}$ School of Biotechnology and \\ Health Sciences, Wuyi University, Jiangmen, China, ${ }^{4}$ Center for Advanced Models for Translational Sciences and \\ Therapeutics, University of Michigan Medical Center, Ann Arbor, MI, United States
}

\section{OPEN ACCESS}

Edited by:

Zhanjun Li,

Jilin University, China

Reviewed by:

Pavel Georgiev,

Institute of Gene Biology (RAS), Russia

Xilong Zheng,

University of Calgary, Canada

${ }^{*}$ Correspondence:

Jianglin Fan

jianglin@yamanashi.ac.jp

Specialty section: This article was submitted to Genomic Assay Technology, a section of the journal

Frontiers in Genetics

Received: 06 October 2020

Accepted: 04 January 2021

Published: 02 February 2021

Citation:

Fan J, Wang Y and Chen YE (2021) Genetically Modified Rabbits for

Cardiovascular Research.

Front. Genet. 12:614379.

doi: 10.3389/fgene.2021.614379
Rabbits are one of the most used experimental animals for investigating the mechanisms of human cardiovascular disease and lipid metabolism because they are phylogenetically closer to human than rodents (mice and rats). Cholesterol-fed wild-type rabbits were first used to study human atherosclerosis more than 100 years ago and are still playing an important role in cardiovascular research. Furthermore, transgenic rabbits generated by pronuclear microinjection provided another means to investigate many gene functions associated with human disease. Because of the lack of both rabbit embryonic stem cells and the genome information, for a long time, it has been a dream for scientists to obtain knockout rabbits generated by homologous recombination-based genomic manipulation as in mice. This obstacle has greatly hampered using genetically modified rabbits to disclose the molecular mechanisms of many human diseases. The advent of genome editing technologies has dramatically extended the applications of experimental animals including rabbits. In this review, we will update genetically modified rabbits, including transgenic, knock-out, and knock-in rabbits during the past decades regarding their use in cardiovascular research and point out the perspectives in future.

Keywords: atherosclerosis, CRISPR-Cas9, hypercholesterolemia, knock-out rabbits, transgenic rabbits

\section{INTRODUCTION}

Rabbits were first used for disclosing the pathogenesis of human atherosclerosis a century ago. In 1908, a Russian physician, Alexander I. Ignatowski (1875-1955) fed rabbits with a diet supplemented with animal proteins (milk, meat, and eggs) and found that these rabbits developed pronounced aortic atherosclerosis.

Later, a Russian experimental pathologist, Nikolai N. Anichkov (or Anitschkow) (1885-1964) further demonstrated that it was dietary cholesterol rather than proteins that play the critical role in the pathogenesis of atherosclerosis in rabbits and proposed a causal role of cholesterol in the development of atherosclerosis (Fan et al., 2015). Now, a consensus has been widely hold in this field that, in both humans and experimental animals, high levels of plasma cholesterol carried by apolipoprotein (apo)-B-containing particles such as low density lipoproteins (LDL) initiate the development of atherosclerosis (Steinberg, 2004). These pioneering studies derived from rabbit experiments not only provided the first evidence but also established a theory basis of the "lipid hypothesis" of atherosclerosis (Steinberg, 2004). Since then, cholesterol-fed rabbits along with Watanabe heritable hyperlipidemic (WHHL) rabbits, a mutant rabbit with genetic deficiency of LDL receptor 
functions, have been extensively used to elucidate multiple facets of the pathophysiology of human atherosclerosis, leading to the discovery of the LDL receptor functions in familial hypercholesterolemia (Goldstein et al., 1983) and the development of the most-prescribed lipid-lowering drug, statin (Brown and Goldstein, 2004). On the other hand, transgenic rabbits with overexpression of various genes were generated from early 90's and served as an alternative tool for investigating the gene functions in cardiovascular disease. Moreover, recent genome editing technology has provided enormous opportunities to create knock-out (KO) and knock-in (KI) rabbits. Important roles of rabbits in studying human atherosclerosis have been extensively reviewed in the previous reviews (Fan et al., 1999a, 2015, 2018; Fan and Watanabe, 2000, 2003). In this review, we will focus on genetically modified rabbits for their applications in cardiovascular research.

\section{"NATURALLY" GENETICALLY MODIFIED RABBITS}

Spontaneous mutations in rabbits can be found accidentally and they can be used in controlling the coat color for commercial purposes such as tyrosinase and the melanocortin 1 receptor (Aigner et al., 2000; Xiao et al., 2019). However, some spontaneous mutations in rabbits can cause a pronounced phenotype that can mimic human diseases, such as Watanabe heritable hyperlipidemic (WHHL) rabbits (Watanabe, 1980), St. Thomas hyperlipidemic rabbits (Laville et al., 1987; Seddon et al., 1987) and complement 6 deficient rabbits (Rother, 1986; Liu et al., 2007a). WHHL rabbits were originally established by Dr. Yoshio Watanabe (1927-2008) at Kobe University, Japan, through serial inbreeding (Watanabe, 1980). Homozygous WHHL rabbits exhibit spontaneous hypercholesterolemia characterized by high levels of LDLs and severe atherosclerosis and often serve as a human familial hypercholesterolemia model (Watanabe et al., 1985). Genetic analysis revealed that WHHL rabbits have defective LDL receptor functions due to a deletion of 12 nucleotides in exon 4 of the LDL receptor gene, which leads to a 4-amino acid deletion in the cysteine-rich ligand-binding domain of the LDL receptor protein (Yamamoto et al., 1986). LDL receptor mutations can be easily detected by PCR analysis (Sun et al., 2002a); however, high levels of plasma LDL-cholesterol are the major manifestation observed in homozygous WHHL rabbits. In addition to hyperlipidemia and aortic atherosclerosis, some WHHL rabbits (later designated as WHHL-MI) show coronary atherosclerosis and myocardial infarction (Shiomi et al., 2003; Shiomi and Fan, 2008). Using WHHL rabbits, Tomoike et al. further developed a subline of WHHL designated a hereditary hypertriglyceridemic rabbit after selected in-breeding. This

Abbreviations: Apo, Apolipoprotein; Cas9, CRISPR-associated (Cas) protein 9; CETP, Cholesteryl ester transfer protein; CRISPR, Clustered regularly interspaced short palindromic repeat; FH, Familial hypercholesterolemia; HDL, High density lipoproteins; IDL, Intermediate density lipoproteins; LDL, Low density lipoproteins; KI, Knock-in; KO, Knock-out; TALEN, Transcription activator-like effector nuclease; Tg, Transgenic; VLDL, Very low density lipoprotein; WHHL, Watanabe heritable hyperlipidemic; ZFN, Zinc finger nuclease. model exhibited postprandial hypertriglyceridemia along with insulin resistance and visceral obesity although polygenetic loci for these pathophysiogical changes have not been determined (Kawai et al., 2006). In addition to WHHL rabbits, the St. Thomas hospital hyperlipidemic rabbits were developed by La Ville et al. in London (Laville et al., 1987; Seddon et al., 1987). Different from WHHL rabbits which have high plasma LDL levels due to LDL receptor dysfunctions, the St. Thomas hospital hyperlipidemic rabbits showed high levels of very low density lipoproteins (VLDL) and intermediate density lipoproteins (IDL), and LDL, thus this rabbit model resembles human familial combined hyperlipidemia. Elevated plasma cholesterol levels in these rabbits were caused by overproduction of these apo-B-containing lipoproteins in the liver although the genetic mutations responsible for hyperlipidemia have not been examined in details. There is a complement-6 (C6) deficient rabbit originally reported by Rother in 1986 (Rother, 1986). C6 deficiency in these rabbits arises from a single gene defect and is not known to be associated with other genetic abnormalities. In spite of this, C6 deficient rabbits are protective against cholesterol diet-induced atherosclerosis (Schmiedt et al., 1998).

\section{TRANSGENIC RABBITS}

Because spontaneous mutant rabbits with obvious phenotypes resembling human disease phenotypes are rare and accidently discovered by experimental animal staff, it is necessary to make genetically modified rabbits according to one's own research purposes. The technology for producing transgenic ( $\mathrm{Tg}$ ) rabbits was almost concurrently reported by German (Brem et al., 1985) and US (Hammer et al., 1985) groups in 1985, but the actual use of $\mathrm{Tg}$ rabbit technology as an experimental tool in the field of cardiovascular diseases was not realized until 1994 when John Taylor's laboratory at the Gladstone Institute of Cardiovascular Disease in San Francisco created the first Tg rabbit expressing human hepatic lipase (Fan et al., 1994). Later on, they also produced $\mathrm{Tg}$ rabbits expressing human apoB-100 (Fan et al., 1995), apoE (Huang et al., 1997; Fan et al., 1998), and apoB mRNA editing protein (Yamanaka et al., 1995). Until now, more than 20 kinds of Tg rabbits expressing different genes that are involved in lipid metabolism and atherosclerosis have been reported and studies using these Tg rabbits have provided considerable insights into the molecular mechanisms of these gene functions in lipoprotein metabolism and atherosclerosis (Fan and Watanabe, 2003; Peng, 2012; Fan et al., 2015). The transgenes expressed in $\mathrm{Tg}$ rabbits for the study of lipoprotein metabolism and atherosclerosis can generally be classified into three categories: (1) those proteins that constitute lipoprotein structures such as apo(a) (Rouy et al., 1998; Fan et al., 1999b), apoAI (Duverger et al., 1996a), apoAII (Koike et al., 2009a; Wang et al., 2013), apoB-100 (Fan et al., 1995), apoCIII (Ding et al., 2011), and apoE (Huang et al., 1997; Fan et al., 1998); (2) those enzymes or transfer proteins that participate in the lipid metabolism such as hepatic lipase (Fan et al., 1994), lipoprotein lipase (Fan et al., 2001a), phospholipid transfer protein (Masson et al., 2011), apoB-100 mRNA editing enzyme catalytic polypeptide protein (Yamanaka et al., 1995), lecithin:cholesterol acyltransferase (Hoeg et al., 
1996), endothelial lipase (Wang et al., 2017); and (3) those proteins that may exert some functions on the arterial wall cells which participate in the pathogenesis of atherosclerosis including matrix metalloproteinase-1,9,12 (Liang et al., 2006; Niimi et al., 2019; Chen et al., 2020), 15-lipoxygenase (Shen et al., 1996), C-reactive protein (Koike et al., 2009b), and vascular endothelial growth factor (Kitajima et al., 2005) (Table 1). In addition, $\mathrm{Tg}$ rabbits have also been used for the investigation of human heart diseases, including LQT syndrome (Brunner et al., 2008), hypertrophic cardiomyopathy (Marian et al., 1999) and tachycardia-induced cardiomyopathy (Suzuki et al., 2009). This is because, in comparison with mice and rats, the rabbit heart is similar to that of humans in both structure and function (Bers, 2002; Marian, 2006; Pogwizd and Bers, 2008). For example, like human heart in which $\beta$-myosin heavy chain $(\beta$-MyHC) accounts for $90 \%$ of total myofibrillar myosin, rabbit heart is composed of $80 \% \beta-\mathrm{MyCH}$ which is different from the mouse heart predominated by $95 \% \alpha-\mathrm{MyHC}$ (Marian, 2005; Bosze et al., 2016). Tg rabbits can be generated by microinjecting a transgenic DNA construct into the pronuclei of fertilized embryos (Fan et al., 1999a; Kitajima et al., 2003). The transgenic constructs are typically composed of the transgene (either cDNA or genomic DNA) under the control of a tissue-specific promoter such as liver- and macrophage-specific promoter. In addition to the pronuclear microinjection method, other methods such as sperm vector (Wang et al., 2003; Li et al., 2006, 2010; Shen et al., 2006), ICSI-mediated transgenesis (Li et al., 2010; Zhang et al., 2016), somatic cell nuclear transfer (SCNT) (Li et al., 2009) or chimeric SCNT (Matsuda et al., 2002; Skrzyszowska et al., 2006), lentiviral vectors (Hiripi et al., 2010), transposonmediated transgenesis (Katter et al., 2013; Ivics et al., 2014), and novel genome editing technology (Song J. et al., 2016; Yang et al., 2016; Li et al., 2019) have been reported to produce Tg rabbits. In spite of this, the pronuclear microinjection is still the most common method even though transgene integration rate is low.

\section{RABBIT EMBRYONIC STEM CELLS AND GENOME INFORMATION}

Because of the lack of both rabbit embryonic stem (ES) cells and the genome information, it has been considered impossible to create KO rabbits by homologous recombination-based genomic modification as to generate $\mathrm{KO}$ mice. Unavailability of $\mathrm{KO}$ rabbits also constitutes another obstacle that hampers researchers to study loss-of-functions of genes in rabbits. We strived to use somatic cell nuclear transfer technique to generate $\mathrm{KO}$ rabbits after Chesne et al. reported the first cloned rabbit about 17 years ago (Chesne et al., 2002). However, after enormous attempts, we got to the conclusion that the production of KO rabbits by somatic cell nuclear transfer is far remote from reality. As a research tool, nuclear transfer technique is unworkable owing to the extraordinarily low efficiency of gene transfer into somatic cells and the possibility in generating cloned rabbits (Song J. et al., 2020). Many groups reported that they could obtain rabbit ES-like cells, but none of these so-called ES-like cells have been proved to be able to generate chimera rabbits (Fan et al., 2015). Rabbit genome has long been an empty area mainly because of budget insufficiency and narrow research communities. In 2014, Carneiro et al. successfully reported a high-quality reference genome using the European rabbit with references to domestication and speciation (Carneiro et al., 2014a,b). Almost at the same period, we along with researchers from the US, Japan and China organized an International Rabbit Genome Sequencing Project Consortium aiming at implementing more extensive whole-genome sequencing of three kinds of common laboratory rabbits: Japanese white rabbits, New Zealand white rabbits and WHHL rabbits. In addition, we performed deep transcriptome sequencing of the aortas, livers, hearts, and kidneys of cholesterol-fed and WHHL rabbits (Wang et al., 2016). After a 2-year collaborative work, we were able to completed whole-genome sequencing of 10 male rabbits for each line with coverage of $13 \mathrm{x}$ for each individual after alignment to the reference genome. With the successful completion of rabbit genome sequencing (Carneiro et al., 2014a,b; Wang et al., 2016), researchers now can easily not only design PCR primers to study gene expression in rabbits but also to generate $\mathrm{KO}$ rabbits using genome editing techniques as described below. Rabbit genome information is now available from the NCBI database and a comprehensive rabbit transcriptome information established by the Chinese Academy of Sciences in Shanghai (Zhou et al., 2018) is also available at http://www.picb.ac.cn/RabGTD/.

\section{KNOCK-OUT AND KNOCK-IN RABBITS BY GENOME EDITING TECHNIQUES}

In the past decade, the emergence of three powerful genome editing technologies has dramatically enhanced the application of genetically modified rabbits (Song J. et al., 2020). The first one is the zinc finger nuclease (ZFN)-mediated genome editing method by which KO rats were successfully created in 2009 (Geurts et al., 2009). Two years later after the birth of KO rats, Flisikowska et al. generated the first immunoglobulin $\mathrm{KO}$ rabbits in an attempt to produce humanized antibodies (Flisikowska et al., 2011). Almost at the same time, we successfully created apoCIII KO rabbits with ZFN-mediated genome editing technology (Yang et al., 2013). ZFNs are engineered DNA-cleaving enzymes made by fusing a tailor-made DNA-binding domain to the DNA cleavage domain of Fok1, a type II restriction enzyme. ZFNs generate site-specific double-strand breaks in the DNA at researcherassigned sites, thus resulting in targeted modification of the genome. However, while ZFNs were not extensively applied in this field, the second generation of the genome editing tool, transcription activator-like effector nucleases (TALEN) were shown up to make the first $\mathrm{KO}$ rats in 2011 (Tesson et al., 2011). TALENs are considered much simpler to design and assemble than ZFNs. The DNA binding domain in TALENs was derived from Xanthomonas spp. Bacteria (Christian et al., 2010; Miller et al., 2011). While TALENs utilize the same Fok I endonuclease domain as ZFNs, its DNA binding domain contains a repeated highly conserved 33-34 amino acid sequence with divergent 12th and 13th amino acids which called Repeat Variable 
TABLE 1 | Transgenic rabbits for the study of human lipoproteins and atherosclerosis.

\begin{tabular}{|c|c|c|c|}
\hline Genes & Expression cells & Major phenotypes & References \\
\hline \multicolumn{4}{|c|}{ Apolipoproteins (apo) } \\
\hline Apo(a) & Liver & Atherogenic & $\begin{array}{l}\text { Rouy et al., 1998; Fan et al., 2001b; Ichikawa et al., 2002; Sun } \\
\text { et al., 2002b; Kitajima et al., } 2007\end{array}$ \\
\hline Apo(a) and apoB & Liver & Not determined & Rouy et al., 1998 \\
\hline ApoA-I & Liver & Athero-protective & Duverger et al., 1996a,b \\
\hline ApoA-II & Liver & Athero-protective & Koike et al., 2009a; Wang et al., 2013 \\
\hline ApoA-I/C-III/A-IV & Liver and intestine & No effect on atherosclerosis & Recalde et al., 2004 \\
\hline ApoB-100 & Liver & LDL $\uparrow, ~ H D L \downarrow$ & Fan et al., 1995 \\
\hline ApoCIII & Liver & VLDL个 & Ding et al., 2011 \\
\hline ApoE2 & Liver & Atherogenic & Huang et al., 1997 \\
\hline ApoE3 & Liver & Atherogenic & Fan et al., 1998; Huang et al., 1999 \\
\hline \multicolumn{4}{|c|}{ Enzymes or transfer proteins } \\
\hline APOPEC1 & Liver & LDL $\downarrow$, liver carcinoma & Yamanaka et al., 1995 \\
\hline APOPEC1 & Knockdown by RNAi & Lean & Jolivet et al., 2014 \\
\hline CETP & Liver & HDL $\downarrow$ & Gao et al., 2017 \\
\hline Endothelial lipase & Liver & Atheroprotective & Wang et al., 2017; Yan et al., 2020b \\
\hline Hepatic lipase & Liver & Athero-protective & Fan et al., 1994 \\
\hline LCAT & Liver & Athero-protective & Hoeg et al., 1996 \\
\hline Lipoprotein lipase & Universal & Athero-protective & Fan et al., 2001a \\
\hline PLTP & Universal & Atherogenic & Masson et al., 2011 \\
\hline \multicolumn{4}{|c|}{ Vascular cell factors } \\
\hline C-reactive protein & Liver & Thrombogenic & Matsuda et al., 2011 \\
\hline Lipoprotein lipase & Macrophage & Atherogenic & Ichikawa et al., 2005 \\
\hline 15-lypooxygenase & Macrophage & Athero-protective & Shen et al., 1996 \\
\hline MMP-1 & Macrophage & Aortic aneurysm $\uparrow$ & Niimi et al., 2019 \\
\hline MMP-9 & Macrophage & Vascular calcification & Chen et al., 2020 \\
\hline MMP-12 & Macrophage & Atherogenic & Liang et al., 2006; Yamada et al., 2008 \\
\hline Urotensin II & Macrophage & Atherogenic & Zhao et al., 2015 \\
\hline VEGF & Liver & Hemangiomas and impaired glomerular functions & Kitajima et al., 2005; Liu et al., 2007b \\
\hline
\end{tabular}

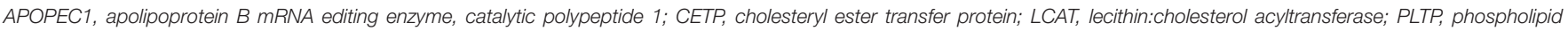
transfer protein; MMP, matrix metalloproteinase; VEGF, vascular endothelial cell growth factor. $\uparrow$, increase; $\downarrow$, decrease.

Diresidue (RVD) for recognizing one specific nucleotide, for example, NN for guanine, NI for adenine, HD for cytosine, and NG for thymine. This direct relationship between amino acid sequence and DNA recognition has made engineering sequence specific binding domains much easier than ZFNs (Boch et al., 2009; Moscou and Bogdanove, 2009). Using TALEN technology, Lai's laboratory at GIBH, immediately generated two kinds of KO rabbits: an immunodeficent KO rabbit with deficiency of Rag1 and Rag2 genes (Song et al., 2013) and fumarylacetoacetate hydrolase deficient rabbits (Li et al., 2017), which mimics human genetic disease tyrosinemia type I, an autosomal recessive disorder caused by mutations in the both copies of the gene encoding the enzyme. Although TALENs are considered superior to ZFNs in terms of fewer off-target effects, easy design and production, it was soon replaced by the CRISPRCas9 based genome editing technology, which is even more rapid and modular than the TALEN platform. Cas9 is an endonuclease playing a protective role against foreign nucleic acids in the adaptive immune system in bacteria. The feature of bacterial CRISPR immune system is that genetic materials taken up from previous invasive elements are expressed in crRNA, which could direct the Cas9 endonuclease to cut foreign DNA elements containing the same sequences (Jinek et al., 2012). Therefore, the CRISPR/Cas9 system has been remolded from bacterial immune system to the genome editing tool, using a designed RNA to guide Cas9 nuclease to the specific DNA sequence (Hsu et al., 2014). Binding of Cas9 nuclease on a specific protospacer adjacent motif (PAM) sequence on the genome (NGG for spCas9) will unwind the adjacent sequence, allowing the RNA:DNA pairing, which activates the nuclease domains in Cas9 to cut DNA and make double-strand breaks. While ZFNs and TALENs rely on proteinDNA recognition, which is less predictable for design and more labor and time consuming for assembly, the CRISPR/Cas9 system relies on the RNA-DNA recognition, which is much simpler and more predictable.

Because CRISPR-Cas9 technique is so efficient and powerful, it was quickly adopted to generate KO rabbits. In this respect, Chen's laboratory at the University of Michigan first established a number of KO rabbits aiming at studying human cardiovascular disease (Yang et al., 2014) and then KO rabbit boom started. Lai's 
laboratory at GIBH and Li's laboratory at Jilin University made more than $30 \mathrm{KO}$ rabbits using CRISPR-Cas9 along with baseediting (Liu et al., 2018) and CRISPR/Cpf1 (Wu et al., 2018). Most $\mathrm{KO}$ rabbits were created in attempt to recapitulate human genetic or congenital disorders or immunodeficient rabbits (Song J. et al., 2017, 2018) as shown in Table 2. In addition, this technique has been tried to target the tyrosinase gene to modify rabbit coat colors (Honda et al., 2015; Song Y. N. et al., 2016, 2017, 2018). The standard protocol for generation of $\mathrm{KO}$ rabbits using CRISPR-Cas9 has been recently published (Yang et al., 2019). The techniques have been further refined (Liu et al., 2018, 2020) so we can predict that in the next few years, more and more $\mathrm{KO}$ or KI rabbits will be made using this technology. Here we will briefly review some valuable $\mathrm{KO}$ rabbits created recently to discuss their usefulness in disclosing the molecular mechanisms of atherosclerosis.

\section{APOCIII KO RABBITS}

ApoCIII is a major component of plasma chylomicrons and VLDLs, and is a minor component of high density lipoproteins (HDLs) and was first reported by Brown et al. 50 years ago (Brown et al., 1969). It is generally believed that physiological functions of apoCIII is to mediate the triglyceride(TG)-rich lipoprotein metabolism thereby maintaining the plasma TG homeostasis and high plasma levels of apoCIII are positively associated with plasma TG and increases the risk of ischemic heart disease (Huff and Hegele, 2013; Norata et al., 2015; Ramms and Gordts, 2018). However, for a long time, it is not clear whether apoCIII was directly involved in the pathogenesis of atherosclerosis because mouse models failed to provide a clear answer (Yan et al., 2020a). Yang et al. first generated apoCIII KO rabbits using ZNF (Yang et al., 2013) and after several years efforts to breed enough numbers of homozygous apoCIII KO rabbits, we were able to examine the hypothesis whether apoCIII may participate in atherosclerosis. Recently, we have shown that that genetic deletion of the apoCIII gene in $\mathrm{KO}$ rabbits significantly accelerates catabolism of TG-rich lipoproteins in the liver and apoCIII deficiency leads to the resistance of $\mathrm{KO}$ rabbits to a cholesterol diet-induced hyperlipidemia and inhibits atherosclerosis (Yan et al., 2020a). These results indicate that therapeutic inhibition of apoCIII expression may become a novel strategy for the treatment of hyperlipidemia and atherosclerosis.

\section{APOE KO RABBITS}

ApoE is a ligand for both LDL receptor and LRP and plays an important role in the catabolism of remnant lipoproteins in the liver and genetic deficiency of apoE is a cause of human type III hyperlipoproteinemia (Mahley, 1988; Mahley et al., 1999). Deletion of apoE in mice even on a normal chow diet exhibited hyperlipidemia along with spontaneous aortic atherosclerosis (Plump et al., 1992; Zhang et al., 1992). ApoE KO rabbits were produced at University of Michigan using CRISPR-Cas9 (Yang et al., 2014) and Sage Company using ZFN (Ji et al., 2015), respectively. Even though different techniques were adopted,
apoE KO rabbits generated by these two methods exhibit the same phenotypes (Niimi et al., 2016). Homozygous apoE KO rabbits on a normal diet only showed mild hyperlipidemia and their plasma total cholesterol levels reached $\sim 200 \mathrm{mg} / \mathrm{dL}$, similar to human type III hyperlipoproteinemia patients, whose cholesterol levels are elevated to $300 \sim 350 \mathrm{mg} / \mathrm{dL}$ (Mahley et al., 1999). Because plasma levels of cholesterol in apoE KO rabbits on a normal diet are not high to be atherogenic, there are not spontaneous atherosclerosis, which is different from apoE $\mathrm{KO}$ mice. However, when apoE KO rabbits were fed a cholesterol diet, they developed more prominent hypercholesterolemia than WT rabbits, which is basically caused by the remarkable accumulation of intestinally-derived remnant lipoproteins, $\beta$-VLDLs (Niimi et al., 2016). Recently, we found that apoE KO rabbits are highly susceptible to a cholesterol diet-induced atherosclerosis. Therefore, apoE KO rabbits will serve as a new model for human hyperlipidemia.

\section{LDL RECEPTOR KO RABBITS}

In humans, genetic deficiency of LDL receptor functions causes severe hypercholesterolemia and atherosclerosis at early ages, called familial hypercholesterolemia (FH). $\mathrm{FH}$ is an autosomal dominant genetic disorder characterized by elevated plasma LDL levels due to LDL receptor dysfunctions (Soutar and Naoumova, 2007). Two laboratories have successfully generated LDL receptor KO rabbits using CRISPR-Cas9 (Yang et al., 2014; Lu et al., 2018). Similar to human FH, homozygous LDL receptor KO rabbits develop spontaneous hypercholesterolemia and atherosclerosis (Lu et al., 2018). Therefore, like WHHL rabbits, LDL receptor KO rabbits can be used for the study of human $\mathrm{FH}$.

\section{CHOLESTERYL ESTER TRANSFER PROTEIN KO RABBITS}

Cholesteryl ester transfer protein (CETP) is a glycoprotein that transfers plasma lipids between HDLs and apoB-containing particles therefore plays an important role in lipoprotein metabolism. However, it is not known whether inhibition of CETP activity can prevent cardiovascular disease because four CETP inhibitors (torcetrapib, dalcetrapib, evacetrapib, and anacetrapib) failed to prove their efficacy in terms of reduction of cardiovascular risk by clinical trials(https://en.wikipedia.org/ wiki/CETP_inhibitor). Since CETP is genetically absent in rodents (mice and rats) and pigs, rabbits are considered the best model for investigation of CETP functions because rabbits have high levels of CETP in the plasma as humans. Taking this advantage, Zhang et al. created CETP KO rabbits and found that CETP KO rabbits showed higher plasma levels of HDLcholesterol (Zhang et al., 2017). When fed a cholesterol-rich diet, CETP KO rabbits still exhibited higher HDL-cholesterol levels accompanied by lower total cholesterol levels than wildtype (WT) rabbits (Zhang et al., 2017). CETP KO rabbits had significant less atherosclerosis in both aorta and coronary arteries than WT rabbits (Zhang et al., 2017). These results indicate 
TABLE 2 | Human congenital disease models of KO rabbits recently created by CRISPR-Cas9 or TALEN.

\begin{tabular}{|c|c|c|c|}
\hline Human diseases & Targeted genes & Major phenotypes & References \\
\hline \multirow[t]{2}{*}{ Congenital cataracts } & $\alpha A-C r y s t a l l i n$ & Cataracts, microphthalmia, obscurity & Yuan et al., 2017 \\
\hline & GJ48 & Microphthalmia, small lens size, and cataracts & Yuan et al., 2016 \\
\hline \multirow[t]{3}{*}{ Muscular dystrophy/hypertrophy } & ANO5 & Muscular dystrophy with increased serum creatine kinase & Sui et al., 2018a \\
\hline & DMD & Impaired physical activity, elevated serum creatine kinase & Sui et al., 2018b \\
\hline & Myostatin & Hyperplasia or hypertrophy of muscle & Lv et al., 2016 (base editing) \\
\hline \multicolumn{4}{|l|}{ Metabolic diseases } \\
\hline & ATP7B & Wilson disease, Death at 3 mon & $\begin{array}{l}\text { Jiang et al., } 2018 \text { (Precision } \\
\text { point mutation) }\end{array}$ \\
\hline & Dentin matrix protein 1 & Mineralization defects & Liu et al., 2019 \\
\hline & GADD45G & Congenital defects cleft palate & Lu et al., 2019 \\
\hline & Glucokinase & Maturity-onset diabetes of the young 2 (MODY2) & Song Y. et al., 2020 \\
\hline & Fumarylacetoacetate hydroxylase & Hereditary tyrosinemia type 1 & Li et al., 2017 (TALEN) \\
\hline & $\mathrm{HOXC13}$ & Hair and nail ectodermal dysplasia & Deng et al., 2019 \\
\hline \multicolumn{4}{|l|}{ Syndromes } \\
\hline & FBN1 & Marfanoid-progeroid-lipodystrophy syndrome & Chen et al., 2018 \\
\hline & SRY & Sex reversal syndromes and hermaphroditism syndromes & Song Y. et al., 2017, 2018 \\
\hline & LMNA & Premature aging syndrome & \\
\hline
\end{tabular}

that genetic ablation of CETP gene inhibits the development of atherosclerosis in cholesterol-fed rabbits.

\section{APOAII KI RABBITS}

ApoAII is the second major apolipoproteins in HDLs. However, its physiological functions are largely unknown compared with apoAI. Interestingly, WT rabbits are genetically deficient in apoAII so their HDLs only contain apoAI. This unique feature makes WT rabbits as a "natural" apoAII KO model. We first made Tg rabbits expressing human apoAII gene and found that hepatic expression of human apoAII inhibits cholesterol dietinduced atherosclerosis (Wang et al., 2013). To examine the apoAII specific functions in the absence of apoAI, we further replaced the rabbit endogenous apoAI with human apoAII gene through knock-in (KI) using TALEN technology (Koike et al., 2021). In this way, apoAII KI rabbits expressed exclusively human apoAII without apoAI in HDL particles, which enables us to compare the net functions of apoAI-only-HDLs in WT rabbits with apoAII-only-HDL in KI rabbits in terms of HDL metabolism and atherosclerosis. In the latest study, we found that apoAII KI rabbits showed consistently lower TG and higher HDL-cholesterol levels and developed significantly less aortic atherosclerosis on a cholesterol diet (Koike et al., 2021).

\section{CONSIDERATIONS AND FUTURE PERSPECTIVES}

Although genetically modified rabbits are an important experimental model in cardiovascular research, they should not be simply used as a substitute of mice and rats, as discussed above. Because rabbits are more expensive, require larger space, and need more time to breed compared with mice, the generation of genetically modified rabbits should be carefully planned to solve those specific problems that cannot be well-examined in other experimental animal models, such as the development of lipid-lowering drugs (Niimi et al., 2020). However, off-target effects in these animals remain a concern as the genome editing is extremely productive and efficient. So far, almost all studies claimed that off-targets in genetically modified rabbits through genome editing are either none or negligible as comprehensively discussed in the recent review (Song J. et al., 2020); nevertheless, there is a need to performed careful genotyping, including sequencing, and expression validation of genetically modified rabbit models. It can be expected that more and more genetically modified rabbits will be made and used in a variety of medical sciences which will certainly expand our knowledge to explore new mechanisms of human diseases. Genome editing technique may eventually replace the pronuclear microinjection for the generation of $\mathrm{Tg}$ rabbits. However, complicated gene manipulation in rabbits, such as conditional KO in an organor cell-specific and time-controlled manner using the Cre/LoxP system is still lacking, thus it will be absolutely necessary to build such a platform in future. Finally, the preservation of valuable strains of genetically modified rabbits is an urgent task with increased number of rabbit models produced. In this aspect, various procedures for cryopreservation of rabbit sperm (Vicente and Viudes-de-Castro, 1996; Dalimata and Graham, 1997; Nishijima et al., 2015) and embryos (al-Hasani et al., 1992; Kasai et al., 1992; Marco-Jimenez et al., 2016) have been reported but have not been standardized. In the future, it may be necessary to establish an international rabbit bio-resource center or sperm and embryo bank to stock and share valuable rabbit models worldwide.

\section{AUTHOR CONTRIBUTIONS}

JF, YW, and YC wrote the manuscript. All authors contributed to the article and approved the submitted version. 


\section{FUNDING}

This work was supported in part by the Research grant from Ono Medical Foundation, JSPS KAKENHI (JP15H04718), the National Natural Science Foundation of China (Nos. 81941001 and 81770457), the JSPS-CAS Bilateral Joint Research Program (JPJSBP 120187204), and NIH grant (HL117491, HL147527, and HL129778).

\section{REFERENCES}

Aigner, B., Besenfelder, U., Muller, M., and Brem, G. (2000). Tyrosinase gene variants in different rabbit strains. Mammalian Genome. 11, 700-702. doi: $10.1007 / \mathrm{s} 003350010120$

al-Hasani, S., Hepnar, C., Diedrich, K., van der Ven, H., and Krebs, D. (1992). Cryopreservation of rabbit zygotes. Human Reprod. 7(Suppl. 1), 81-83. doi: 10.1093/humrep/7.suppl_1.81

Bers, D. M. (2002). Cardiac $\mathrm{Na} / \mathrm{Ca}$ exchange function in rabbit, mouse and man: what's the difference? J. Mol. Cell Cardiol. 34, 369-73. doi: 10.1006/jmcc.2002.1530

Boch, J., Scholze, H., Schornack, S., Landgraf, A., Hahn, S., Kay, S., et al. (2009). Breaking the code of DNA binding specificity of TAL-Type III effectors. Science 326, 1509-1512. doi: 10.1126/science.1178811

Bosze, Z., Major, P., Baczkó I., Odening, K. E., Bodrogi, L., Hiripi, L., et al. (2016). The potential impact of new generation transgenic methods on creating rabbit models of cardiac diseases. Prog. Biophys. Mol. Biol. 121, 123-130. doi: 10.1016/j.pbiomolbio.2016.05.007

Brem, G., Brenig, B., Goodman, H. M., Selden, R. C., Graf, F., Kruff, B., et al. (1985). Production of transgenic mice, rabbits and pigs by microinjection into pronuclei. Zuchthygiene-Reproduct. Domestic Animals 20, 251-252. doi: 10.1111/j.1439-0531.1985.tb00423.x

Brown, M. S., and Goldstein, J. L. (2004). A tribute to Akira Endo, discoverer of a "Penicillin" for cholesterol. Atheroscler. Suppl. 5, 13-16. doi: 10.1016/j.atherosclerosissup.2004.08.007

Brown, W. V., Levy, R. I., and Fredrickson, D. S. (1969). Studies of the proteins in human plasma very low density lipoproteins. J. Biol. Chem. 244, 5687-5694. doi: 10.1016/S0021-9258(18)63614-2

Brunner, M., Peng, X., Liu, G. X., Ren, X. Q., Ziv, O., Choi, B. R., et al. (2008). Mechanisms of cardiac arrhythmias and sudden death in transgenic rabbits with long QT syndrome. J. Clin. Invest. 118, 2246-2259. doi: 10.1172/JCI33578

Carneiro, M., Albert, F. W., Afonso, S., Pereira, R. J., Burbano, H., Campos, R., et al. (2014a). The genomic architecture of population divergence between subspecies of the european rabbit. PLoS Genet. 10:e1003519. doi: 10.1371/journal.pgen.1003519

Carneiro, M., Rubin, C. J., Di Palma, F., Albert, F. W., Alfoldi, J., Barrio, A. M., et al. (2014b). Rabbit genome analysis reveals a polygenic basis for phenotypic change during domestication. Science 345, 1074-1079. doi: 10.1126/science.1253714

Chen, M., Yao, B., Yang, Q., Deng, J., Song, Y., Sui, T., et al. (2018). Truncated C-terminus of fibrillin-1 induces Marfanoid-progeroidlipodystrophy (MPL) syndrome in rabbit. Dis. Model. Mech. 11:dmm031542. doi: $10.1242 / \mathrm{dmm} .031542$

Chen, Y., Waqar, A. B., Nishijima, K., Ning, B., Kitajima, S., Matsuhisa, F., et al. (2020). Macrophage-derived MMP-9 enhances the progression of atherosclerotic lesions and vascular calcification in transgenic rabbits. J. Cell Mol. Med. 24, 4261-4274. doi: 10.1111/jcmm.15087

Chesne, P., Adenot, P. G., Viglietta, C., Baratte, M., Boulanger, L., and Renard, J. P. (2002). Cloned rabbits produced by nuclear transfer from adult somatic cells. Nat. Biotechnol. 20, 366-369. doi: 10.1038/nbt0402-366

Christian, M., Cermak, T., Doyle, E. L., Schmidt, C., Zhang, F., Hummel, A., et al. (2010). Targeting DNA double-strand breaks with TAL effector nucleases. Genetics 186, 757-761. doi: 10.1534/genetics.110.120717

Dalimata, A. M., and Graham, J. K. (1997). Cryopreservation of rabbit spermatozoa using acetamide in combination with trehalose and methyl cellulose. Theriogenology 48, 831-841. doi: 10.1016/S0093-691X(97)00305-1

\section{ACKNOWLEDGMENTS}

We would like to thank the following people for their contribution to this project. Jun Song, Jie $\mathrm{Xu}$, Dongshan Yang, and Jifeng Zhang at the University of Michigan, Yajie Chen, Tomonari Koike, and Manabu Niimi at University of Yamanashi, and Shuji Kitajima and Fumikazu Matsuhisa at Saga University.

Deng, J. C., Chen, M., Liu, Z. Q., Song, Y. N., Sui, T. T., Lai, L. X., et al. (2019). The disrupted balance between hair follicles and sebaceous glands in Hoxc13-ablated rabbits. FASEB J. 33, 1226-1234. doi: 10.1096/fj.201800928RR

Ding, Y., Wang, Y., Zhu, H., Fan, J., Yu, L., Liu, G., et al. (2011). Hypertriglyceridemia and delayed clearance of fat load in transgenic rabbits expressing human apolipoprotein CIII. Transgenic Res. 20, 867-875. doi: 10.1007/s11248-010-9467-5

Duverger, N., Kruth, H., Emmanuel, F., Caillaud, J. M., Viglietta, C., Castro, G., et al. (1996a). Inhibition of atherosclerosis development in cholesterolfed human apolipoprotein A-I-transgenic rabbits. Circulation 94, 713-717. doi: 10.1161/01.CIR.94.4.713

Duverger, N., Viglietta, C., Berthou, L., Emmanuel, F., Tailleux, A., Parmentier-Nihoul, L., et al. (1996b). Transgenic rabbits expressing human apolipoprotein A-I in the liver. Arterioscl. Thromb. Vasc. Biol. 16, 1424-1429. doi: 10.1161/01.ATV.16.12.1424

Fan, J., Araki, M., Wu, L., Challah, M., Shimoyamada, H., Lawn, M. R., et al. (1999b). Assembly of lipoprotein (a) in transgenic rabbits expressing human apolipoprotein (a). Biochem. Biophy. Res. Commun. 255, 639-644. doi: 10.1006/bbrc.1999.0242

Fan, J., Challah, M., and Watanabe, T. (1999a). Transgenic rabbit models for biomedical research: current status, basic methods and future perspectives. Pathol. Int. 49, 583-594. doi: 10.1046/j.1440-1827.1999.00923.x

Fan, J., Chen, Y., Yan, H., Niimi, M., Wang, Y., and Liang, J. (2018). Principles and applications of rabbit models for atherosclerosis research. J. Atheroscler. Thromb. 25, 213-220. doi: 10.5551/jat.RV17018

Fan, J., Ji, Z.-S., Huang, Y., de Silva, H., Sanan, D., Mahley, R., et al. (1998). Increased expression of apolioprotein $\mathrm{E}$ in transgenic rabbits results in reduced levels of very low density lipoproteins and an accumulation of low density lipoproteins in plasma. J. Clin. Invest. 101, 2151-2164. doi: 10.1172/JCI1599

Fan, J., Kitajima, S., Watanabe, T., Xu, J., Zhang, J., Liu, E., et al. (2015). Rabbit models for the study of human atherosclerosis: from pathophysiological mechanisms to translational medicine. Pharmacol. Ther. 146, 104-119. doi: 10.1016/j.pharmthera.2014.09.009

Fan, J., McCormick, S. P., Krauss, R. M., Taylor, S., Quan, R., Taylor, J. M., et al. (1995). Overexpression of human apolipoprotein B-100 in transgenic rabbits results in increased levels of LDL and decreased levels of HDL. Arterioscler. Thromb. Vascu. Biol. 15, 1889-1899. doi: 10.1161/01.ATV.15.11.1889

Fan, J., Shimoyamada, H., Sun, H., Marcovina, S., Honda, K., and Watanabe, T. (2001a). Transgenic rabbits expressing human apolipoprotein(a) develop more extensive atherosclerotic lesions in response to a cholesterol-rich diet. Arterioscler. Thromb. Vasc. Biol. 21, 88-94. doi: 10.1161/01.ATV.21.1.88

Fan, J., Unoki, H., Kojima, N., Sun, H., Shimoyamada, H., Deng, H., et al. (2001b). Overexpression of lipoprotein lipase in transgenic rabbits inhibits diet-induced hypercholesterolemia and atherosclerosis. J. Biol. Chem. 276, 40071-40079. doi: 10.1074/jbc.M105456200

Fan, J., Wang, J., Bensadoun, A., Lauer, S. J., Dang, Q., Mahley, R. W., et al. (1994). Overexpression of hepatic lipase in transgenic rabbits leads to a marked reduction of plasma high density lipoproteins and intermediate density lipoproteins. Proc. Natl. Acad. Sci. U.S.A. 91, 8724-8728. doi: 10.1073/pnas.91.18.8724

Fan, J., and Watanabe, T. (2000). Cholesterol-fed and transgenic rabbit models for the study of atherosclerosis. J. Atheroscler. Thromb. 7, 26-32. doi: 10.5551/jat1994.7.26

Fan, J., and Watanabe, T. (2003). Transgenic rabbits as therapeutic protein bioreactors and human disease models. Pharmacol. Ther. 99, 261-282. doi: 10.1016/S0163-7258(03)00069-X 
Flisikowska, T., Thorey, I. S., Offner, S., Ros, F., Lifke, V., Zeitler, B., et al. (2011). Efficient immunoglobulin gene disruption and targeted replacement in rabbit using zinc finger nucleases. PLoS ONE. 6:e21045. doi: 10.1371/journal.pone.0021045

Gao, S., Wang, X., Cheng, D., Li, J., Li, L., Ran, L., et al. (2017). Overexpression of cholesteryl ester transfer protein increases macrophage-derived foam cell accumulation in atherosclerotic lesions of transgenic rabbits. Mediators Inflamm. 2017:3824276. doi: 10.1155/2017/3824276

Geurts, A. M., Cost, G. J., Freyvert, Y., Zeitler, B., Miller, J. C., Choi, V. M., et al. (2009). Knockout rats via embryo microinjection of zinc-finger nucleases. Science 325:433. doi: 10.1126/science.1172447

Goldstein, J. L., Kita, T., and Brown, M. S. (1983). Defective lipoprotein receptors and atherosclerosis. Lessons from an animal counterpart of familial hypercholesterolemia. N. Engl. J. Med. 309, 288-296. doi: 10.1056/NEJM198308043090507

Hammer, R. E., Pursel, V. G., Rexroad, C. E. Jr., Wall, R. J., Bolt, D. J., Ebert, K. M., et al. (1985). Production of transgenic rabbits, sheep and pigs by microinjection. Nature 315, 680-683. doi: 10.1038/315680a0

Hiripi, L., Negre, D., Cosset, F. L., Kvell, K., Czompoly, T., Baranyi, M., et al. (2010). Transgenic rabbit production with simian immunodeficiency virus-derived lentiviral vector. Transgenic Res. 19, 799-808. doi: 10.1007/s11248-009-9356-y

Hoeg, J. M., Santamarina-Fojo, S., Berard, A. M., Cornhill, J. F., Herderick, E. E., Feldman, S. H., et al. (1996). Overexpression of lecithin:cholesterol acyltransferase in transgenic rabbits prevents diet-induced atherosclerosis. Proc. Natl. Acad. Sci. U.S.A. 93, 11448-11453. doi: 10.1073/pnas.93.21.11448

Honda, A., Hirose M., Sankai, T., Yasmin, L., Yuzawa, K., Honsho, K., et al. (2015). Single-step generation of rabbits carrying a targeted allele of the tyrosinase gene using CRISPR/Cas9. Exp. Animals 64, 31-37. doi: 10.1538/expanim.14-0034

Hsu, P. D., Lander, E. S., and Zhang, F. (2014). Development and applications of CRISPR-Cas9 for genome engineering. Cell 157, 1262-1278. doi: 10.1016/j.cell.2014.05.010

Huang, Y., Ji, Z. S., Brecht, W. J., Rall, S. C. Jr., Taylor, J. M., and Mahley, R. W. (1999). Overexpression of apolipoprotein E3 in transgenic rabbits causes combined hyperlipidemia by stimulating hepatic VLDL production and impairing VLDL lipolysis. Arterioscler. Thromb. Vasc. Biol. 19, 2952-2959. doi: 10.1161/01.ATV.19.12.2952

Huang, Y., Schwendner, S. W., Rall, S. C. J., Sanan, D. A., and Mahley, R. W. (1997). Apolipoprotein E2 transgenic rabbits. J. Biol. Chem. 272, 22685-22694. doi: $10.1074 / j b c .272 .36 .22685$

Huff, M. W., and Hegele, R. A. (2013). Apolipoprotein C-III: going back to the future for a lipid drug target. Circ. Res. 112, 1405-1408. doi: 10.1161/CIRCRESAHA.113.301464

Ichikawa, T., Liang, J., Kitajima, S., Koike, T., Wang, X., Sun, H., et al. (2005). Macrophage-derived lipoprotein lipase increases aortic atherosclerosis in cholesterol-fed $\mathrm{Tg}$ rabbits. Atherosclerosis 179, 87-95. doi: 10.1016/j.atherosclerosis.2004.10.044

Ichikawa, T., Unoki, H., Sun, H., Shimoyamada, H., Marcovina, S., Shikama, H., et al. (2002). Lipoprotein(a) promotes smooth muscle cell proliferation and dedifferentiation in atherosclerotic lesions of human apo(a) transgenic rabbits. Am. J. Pathol. 160, 227-236. doi: 10.1016/S0002-9440(10)64366-0

Ivics, Z., Hiripi, L., Hoffmann, O. I., Mates, L., Yau, T. Y., Bashir, S., et al. (2014). Germline transgenesis in rabbits by pronuclear microinjection of Sleeping Beauty transposons. Nat. Protoc. 9, 794-809. doi: 10.1038/nprot.2014.009

Ji, D., Zhao, G., Songstad, A., Cui, X., and Weinstein, E. J. (2015). Efficient creation of an APOE knockout rabbit. Transgenic Res. 24, 227-235. doi: 10.1007/s11248-014-9834-8

Jiang, W., Liu, L., Chang, Q., Xing, F., Ma, Z., Fang, Z., et al. (2018). Production of wilson disease model rabbits with homology-directed precision point mutations in the ATP7B gene using the CRISPR/Cas9 system. Sci. Rep. 8:1332. doi: 10.1038/s41598-018-19774-4

Jinek, M., Chylinski, K., Fonfara, I., Hauer, M., Doudna, J. A., and Charpentier, E. (2012). A programmable Dual-RNA-guided DNA endonuclease in adaptive bacterial immunity. Science 337, 816-821. doi: 10.1126/science.12 25829

Jolivet, G., Braud, S., DaSilva, B., Passet, B., Harscoet, E., Viglietta, C., et al. (2014). Induction of body weight loss through RNAi-knockdown of APOBEC1 gene expression in transgenic rabbits. PLoS ONE 9:e106655. doi: 10.1371 /journal.pone. 0106655
Kasai, M., Hamaguchi, Y., Zhu, S. E., Miyake, T., Sakurai, T., and Machida, T. (1992). High survival of rabbit morulae after vitrification in an ethylene glycol-based solution by a simple method. Biol. Reprod. 46, 1042-1046. doi: 10.1095/biolreprod46.6.1042

Katter, K., Geurts, A. M., Hoffmann, O., Mates, L., Landa, V., Hiripi, L., et al. (2013). Transposon-mediated transgenesis, transgenic rescue, and tissuespecific gene expression in rodents and rabbits. FASEB J. 27, 930-941. doi: 10.1096/fj.12-205526

Kawai, T., Ito, T., Ohwada, K., Mera, Y., Matsushita, M., and Tomoike, H. (2006). Hereditary postprandial hypertriglyceridemic rabbit exhibits insulin resistance and central obesity - a novel model of metabolic syndrome. Arterioscleros. Thrombo. Vasc. Biol. 26, 2752-2757. doi: 10.1161/01.ATV.0000245808.12493.40

Kitajima, S., Jin, Y., Koike, T., Yu, Y., Liu, E., Shiomi, M., et al. (2007). $\mathrm{Lp}$ (a) enhances coronary atherosclerosis in transgenic Watanabe heritable hyperlipidemic rabbits. Atherosclerosis 193, 269-276. doi: 10.1016/j.atherosclerosis.2006.08.056

Kitajima, S., Liu, E., Morimoto, M., Koike, T., Yu, Y., Watanabe, T., et al. (2005). Transgenic rabbits with increased VEGF expression develop hemangiomas in the liver: a new model for Kasabach-Merritt syndrome. Lab. Invest. 85, 1517-1527. doi: 10.1038/labinvest.3700346

Kitajima, S., Morimoto, M., Watanabe, T., and Fan, J. (2003). Transgenic rabbits: production and applications for human disease models. Res. Dev. Biophy. Biochem. 3, 179-194.

Koike, K., Koike, Y., Yang, D., Guo, Y., Song, J., Xu, J., et al. (2021). Human apolipoprotein A-II reduces atherosclerosis in knock-in rabbits. Atherosclerosis 316, 32-40. doi: 10.1016/j.atherosclerosis.2020.11.028

Koike, T., Kitajima, S., Yu, Y., Li, Y., Nishijima, K., Liu, E., et al. (2009a). Expression of human apoAII in transgenic rabbits leads to dyslipidemia: a new model for combined hyperlipidemia. Arterioscler. Thromb. Vasc. Biol. 29, 2047-2053. doi: 10.1161/ATVBAHA.109.190264

Koike, T., Kitajima, S., Yu, Y., Nishijima, K., Zhang, J., Ozaki, Y., et al. (2009b). Human C-reactive protein does not promote atherosclerosis in transgenic rabbits. Circulation. 120, 2088-2094. doi: 10.1161/CIRCULATIONAHA.109.872796

Laville, A., Turner P. R., Pittilo, R. M., Martini, S., Marenah, C. B., Rowles, P. M., et al. (1987). Hereditary Hyperlipidemia in the rabbit due to overproduction of Lipoproteins 1. biochemical-studies. Arteriosclerosis 7, 105-112. doi: 10.1161/01.ATV.7.2.105

Li, H., Li, Z., Xiao, N., Su, X., Zhao, S., Zhang, Y., et al. (2019). Sitespecific integration of rotavirus VP6 gene in rabbit beta-casein locus by CRISPR/Cas9 system. In Vitro Cell. Dev. Biol. Anim. 55, 586-597. doi: $10.1007 / \mathrm{s} 11626-019-00382-\mathrm{z}$

Li, L., Shen, W., Min, L., Dong, H., Sun, Y., and Pan, Q. (2006). Human lactoferrin transgenic rabbits produced efficiently using dimethylsulfoxidesperm-mediated gene transfer. Reproduc. Fertil. Dev. 18, 689-695. doi: 10.1071/RD06001

Li, L., Zhang, Q., Yang, H., Zou, Q., Lai, C., Jiang, F., et al. (2017). Fumarylacetoacetate hydrolase knock-out rabbit model for hereditary tyrosinemia Type 1. J. Biol. Chem. 292, 4755-4763. doi: 10.1074/jbc.M116.764787

Li, Q., Hou, J., Wang, S., Chen, Y., and An, X. R. (2010). Production of transgenic rabbit embryos through intracytoplasmic sperm injection. Zygote 18, 301-307. doi: 10.1017/S0967199410000250

Li, S., Guo, Y., Shi, J., Yin, C., Xing, F., Xu, L., et al. (2009). Transgene expression of enhanced green fluorescent protein in cloned rabbits generated from in vitro-transfected adult fibroblasts. Transgenic Res. 18, 227-235. doi: 10.1007/s11248-008-9227-y

Liang, J., Liu, E., Yu, Y., Kitajima, S., Koike, T., Jin, Y., et al. (2006). Macrophage metalloelastase accelerates the progression of atherosclerosis in transgenic rabbits. Circulation 113, 1993-2001. doi: 10.1161/CIRCULATIONAHA.105.596031

Liu, E., Kitajima, S., Wiese, E., Reifenberg, K., Morimoto, M., Watanabe, T., et al. (2007a). Re-establishment of complement C6-deficient rabbit colony by cryopreserved sperm transported from abroad. Exp. Anim. 56, 167-171. doi: 10.1538/expanim.56.167

Liu, E., Morimoto, M., Kitajima, S., Koike, T., Yu, Y., Shiiki, H., et al. (2007b). Increased expression of vascular endothelial growth factor in kidney leads 
to progressive impairment of glomerular functions. J. Am. Soc. Nephrol. 18, 2094-2104. doi: 10.1681/ASN.2006010075

Liu, T. J., Wang, J., Xie, X. D., Wang, K., Sui, T. T., Liu, D., et al. (2019). DMP1 Ablation in the rabbit results in mineralization defects and abnormalities in haversian Canal/Osteon microarchitecture. J. Bone Mineral Res. 34, 1115-1128. doi: 10.1002/jbmr.3683

Liu, Z. Q., Chen, M., Chen, S. Y., Deng, J. C., Song, Y. N., Lai, L. X., et al. (2018). Highly efficient RNA-guided base editing in rabbit. Nat. Commun. 9:2717. doi: 10.1038/s41467-018-05232-2

Liu, Z. Q., Shan, H. H., Chen, S. Y., Chen, M., Song, Y. N., Lai, L. X., et al. (2020). Highly efficient base editing with expanded targeting scope using SpCas9-NG in rabbits. FASEB J. 34, 588-596. doi: 10.1096/fj.201901587R

Lu, R., Yuan, T., Wang, Y., Zhang, T., Yuan, Y., Wu, D., et al. (2018). Spontaneous severe hypercholesterolemia and atherosclerosis lesions in rabbits with deficiency of low-density lipoprotein receptor (LDLR) on exon 7 . EBioMedicine 36, 29-38. doi: 10.1016/j.ebiom.2018.09.020

Lu, Y., Liang, M. M., Zhang, Q. J., Liu, Z. Q., Song, Y. N., Lai, L. X., et al. (2019). Mutations of GADD45G in rabbits cause cleft lip by the disorder of proliferation, apoptosis and epithelial-mesenchymal transition (EMT). Biochim. Biophys. Acta Mol. Basis Dis. 1865, 2356-2367. doi: 10.1016/j.bbadis.2019.05.015

Lv, Q., Yuan, L., Deng, J., Chen, M., Wang, Y., Zeng, J., et al. (2016). Efficient generation of myostatin gene mutated rabbit by CRISPR/Cas9. Sci. Rep. 6:25029. doi: 10.1038/srep25029

Mahley, R. W. (1988). Apolipoprotein E:cholesterol transport protein with expanding role in cell biology. Science 240, 622-30. doi: $10.1126 /$ science. 3283935

Mahley, R. W., Huang, Y., and Rall, S. C. (1999). Pathogenesis of type III hyperlipoproteinemia (dysbetalipoproteinemia). questions, quandaries, and paradoxes. J. Lipid Res. 40, 1933-1949.

Marco-Jimenez, F., Jimenez-Trigos, E., Almela-Miralles, V., and Vicente, J. S. (2016). Development of cheaper embryo vitrification device using the minimum volume method. PLoS ONE 11:e0148661. doi: 10.1371 /journal.pone.0148661

Marian, A. J. (2005). On mice, rabbits, and human heart failure. Circulation 111, 2276-2279. doi: 10.1161/01.CIR.0000167559.13502.9A

Marian, A. J. (2006). Beta-adrenergic receptors signaling and heart failure in mice, rabbits and humans. J. Mol. Cell Cardiol. 41, 11-3. doi: 10.1016/j.yjmcc.2006.04.001

Marian, A. J., Wu, Y., Lim, D. S., McCluggage, M., Youker, K., Yu, Q. T., et al. (1999). A transgenic rabbit model for human hypertrophic cardiomyopathy. J. Clin. Invest. 104, 1683-1692. doi: 10.1172/JCI7956

Masson, D., Deckert, V., Gautier, T., Klein, A., Desrumaux, C., Viglietta, C., et al. (2011). Worsening of diet-induced atherosclerosis in a new model of transgenic rabbit expressing the human plasma phospholipid transfer protein. Arterioscler. Thromb. Vasc. Biol. 31, 766-74. doi: 10.1161/ATVBAHA.110.2 15756

Matsuda, J., Takahashi, S., Ohkoshi, K., Kaminaka, K., Kaminaka, S., Nozaki, C., et al. (2002). Production of transgenic chimera rabbit fetuses using somatic cell nuclear transfer. Cloning Stem Cells 4, 9-19. doi: 10.1089/1536230027536 32002

Matsuda, S., Yamashita, A., Sato, Y., Kitajima, S., Koike, T., Sugita, C., et al. (2011). Human C-reactive protein enhances thrombus formation after neointimal balloon injury in transgenic rabbits. J. Thromb. Haemost. 9, 201-208. doi: 10.1111/j.1538-7836.2010.04086.x

Miller, J. C., Tan, S. Y., Qiao, G. J., Barlow, K. A., Wang, J. B., Xia, D. F., et al. (2011). A TALE nuclease architecture for efficient genome editing. Nat. Biotechnol. 29, 143-U149. doi: 10.1038/nbt.1755

Moscou, M. J., and Bogdanove, A. J. (2009). A simple cipher governs DNA recognition by TAL effectors. Science 326, 1501-1501. doi: $10.1126 /$ science. 1178817

Niimi, M., Chen, J., Yan, H., Wang, Y., Koike, T., and Fan, J. (2020). Hyperlipidemic rabbit models for anti-atherosclerotic drug development. Appl. Sci. 10:8681. doi: 10.3390/app10238681

Niimi, M., Nishijima, K., Kitajima, K., Matsuhisa, F., Koike, Y., Koike, K., et al. (2019). Macrophage-derived matrix metalloproteinase-1 accelerates aortic aneurysm formation in transgenic rabbits. J. Biomed. Res. 33, 271-279. doi: 10.7555/JBR.33.20180097
Niimi, M., Yang, D., Kitajima, S., Ning, B., Wang, C., Li, S., et al. (2016). ApoE knockout rabbits: a novel model for the study of human hyperlipidemia. Atherosclerosis 245, 187-193. doi: 10.1016/j.atherosclerosis.2015.12.002

Nishijima, K., Kitajima, S., Koshimoto, C., Morimoto, M., Watanabe, T., Fan, J., et al. (2015). Motility and fertility of rabbit sperm cryopreserved using soybean lecithin as an alternative to egg yolk. Theriogenology 84, 1172-1175. doi: 10.1016/j.theriogenology.2015.06.018

Norata, G. D., Tsimikas, S., Pirillo, A., and Catapano, A. L. (2015). Apolipoprotein C-III: from pathophysiology to pharmacology. Trends Pharmacol. Sci. 36, 675-687. doi: 10.1016/j.tips.2015.07.001

Peng, X. (2012). Transgenic rabbit models for studying human cardiovascular diseases. Comp. Med. 62, 472-9.

Plump, A. S., Smith, J. D., Hayek, T., Aalto-Setala, K., Walsh, A., Verstuyft, J. G., et al. (1992). Severe hypercholesterolemia and atherosclerosis in apolipoprotein E-deficient mice created by homologous recombination in ES cells. Cell 71, 343-353. doi: 10.1016/0092-8674(92) 90362-G

Pogwizd, S. M., and Bers, D. M. (2008). Rabbit models of heart disease. Drug Discov. Today Dis. Models 5, 185-193. doi: 10.1016/j.ddmod.2009.02.001

Ramms, B., and Gordts, P. (2018). Apolipoprotein C-III in triglyceriderich lipoprotein metabolism. Curr. Opin. Lipidol. 29, 171-179. doi: 10.1097/MOL.0000000000000502

Recalde, D., Baroukh, N., Viglietta, C., Prince, S., Verona, J., Vergnes, L., et al. (2004). Marie houdebine, human apoA-I/C-III/A-IV gene cluster transgenic rabbits: effects of a high-cholesterol diet. FEBS Lett. 572, 294-298. doi: 10.1016/j.febslet.2004.07.041

Rother, K. (1986). Rabbits deficient in C6. Prog. Allergy 39, 192-201. doi: $10.1159 / 000318545$

Rouy, D., Duverger, N., Lin, S. D., Emmanuel, F., Houdebine, L. M., Denefle, P., et al. (1998). Apolipoprotein(a) yeast artificial chromosome transgenic rabbits. Lipoprotein(a) assembly with human and rabbit apolipoprotein B. J. Biol. Chem. 273, 1247-1251. doi: 10.1074/jbc.273.2.1247

Schmiedt, W., Kinscherf, R., Deigner, H. P., Kamencic, H., Nauen, O., Kilo, J., et al. (1998). Complement C6 deficiency protects against diet-induced atherosclerosis in rabbits. Arterioscleros. Thromb. Vasc. Biol. 18, 1790-1795. doi: 10.1161/01.ATV.18.11.1790

Seddon, A. M., Woolf, N., Laville, A., Pittilo, R. M., Rowles, P. M., Turner, P. R., et al. (1987). Hereditary Hyperlipidemia and Atherosclerosis in the rabbit due to overproduction of Lipoproteins.2. preliminary-report of arterial pathology. Arteriosclerosis 7, 113-124. doi: 10.1161/01.ATV.7.2.113

Shen, J., Herderick, E., Cornhill, J. F., Zsigmond, E., Kim, H. S., Kuhn, H., et al. (1996). Macrophage-mediated 15-lipoxygenase expression protects against atherosclerosis development. J. Clin. Invest. 98, 2201-2208. doi: 10.1172/JCI119029

Shen, W., Li, L., Pan, Q., Min, L., Dong, H., and Deng, J. (2006). Efficient and simple production of transgenic mice and rabbits using the new DMSO-sperm mediated exogenous DNA transfer method. Mol. Reprod. Dev. 73, 589-594. doi: $10.1002 / \mathrm{mrd} .20401$

Shiomi, M., and Fan, J. (2008). Unstable coronary plaques and cardiac events in myocardial infarction-prone Watanabe heritable hyperlipidemic rabbits: questions and quandaries. Curr. Opin. Lipidol. 19, 631-636. doi: 10.1097/MOL.0b013e3283189c18

Shiomi, M., Ito, T., Yamada, S., Kawashima, S., and Fan, J. (2003). Development of an animal model for spontaneous myocardial infarction (WHHLMI rabbits). Arterioscler. Thromb. Vasc. Biol. 23, 1239-1244. doi: 10.1161/01.ATV.0000075947.28567.50

Skrzyszowska, M., Smorag, Z., Slomski, R., Katska-Ksiazkiewicz, L., Kalak, R., Michalak, E., et al. (2006). Generation of transgenic rabbits by the novel technique of chimeric somatic cell cloning. Biol. Reprod. 74, 1114-1120. doi: 10.1095/biolreprod.104.039370

Song, J., Wang, G. S., Hoenerhoff, M. J., Ruan, J. X., Yang, D. S., Zhang, J. F., et al. (2018). Bacterial and pneumocystis infections in the lungs of geneknockout rabbits with severe combined immunodeficiency. Front. Immunol. 9:429. doi: 10.3389/fimmu.2018.00429

Song, J., Yang, D., Xu, J., Zhu, T., Chen, Y. E., and Zhang, J. (2016). RS-1 enhances CRISPR/Cas9- and TALEN-mediated knockin efficiency. Nat. Commun. 7:10548. doi: 10.1038/ncomms1 0548 
Song, J., Yang, D. S., Ruan, J. X., Zhang, J. F., Chen, Y. E., and Xu, J. (2017). Production of immunodeficient rabbits by multiplex embryo transfer and multiplex gene targeting. Sci. Rep. 7:12202. doi: 10.1038/s41598-017-12201-0

Song, J., Zhang, J., Xu, J., Garcia-Barrio, M., Chen, Y. E., and Yang, D. (2020). Genome engineering technologies in rabbits. J. Biomed. Res. 34, 1-13. doi: 10.7555/JBR.34.20190133

Song, J., Zhong, J., Guo, X., Chen, Y., Zou, Q., Huang, J., et al. (2013). Generation of RAG 1- and 2-deficient rabbits by embryo microinjection of TALENs. Cell Res. 23, 1059-1062. doi: 10.1038/cr.2013.85

Song, Y., Liu, T., Wang, Y., Deng, J., Chen, M., Yuan, L., et al. (2017). Mutation of the Sp1 binding site in the 5' flanking region of SRY causes sex reversal in rabbits. Oncotarget 8, 38176-38183. doi: 10.18632/oncotarget.16979

Song, Y., Sui, T., Zhang, Y., Wang, Y., Chen, M., Deng, J., et al. (2020). Genetic deletion of a short fragment of glucokinase in rabbit by CRISPR/Cas9 leading to hyperglycemia and other typical features seen in MODY-2. Cell. Mol. Life Sci. 77, 3265-3277. doi: 10.1007/s00018-019-03354-4

Song, Y., Xu, Y., Liang, M., Zhang, Y., Chen, M., Deng, J., et al. (2018). CRISPR/Cas9-mediated mosaic mutation of SRY gene induces hermaphroditism in rabbits. Biosci. Rep. 38:BSR20171490. doi: 10.1042/BSR20171490

Song, Y. N., Xu, Y. X., Deng, J. C., Chen, M., Lu, Y., Wang, Y., et al. (2017). CRISPR/Cas9-mediated mutation of tyrosinase (Tyr) 3 ' UTR induce graying in rabbit. Sci. Rep. 7:1569. doi: 10.1038/s41598-017-01727-y

Song, Y. N., Yuan, L., Wang, Y., Chen, M., Deng, J. C., Lv, Q. Y., et al. (2016). Efficient dual sgRNA-directed large gene deletion in rabbit with CRISPR/Cas9 system. Cell. Mol. Life Sci. 73, 2959-2968. doi: 10.1007/s00018-016-2143-Z

Song, Y. N., Zhang, Y. X., Chen, M., Deng, J. C., Sui, T. T., Lai, L. X., et al. (2018). Functional validation of the albinism-associated tyrosinase T373K SNP by CRISPR/Cas9-mediated homology-directed repair (HDR) in rabbits. Ebiomedicine 36, 517-525. doi: 10.1016/j.ebiom.2018.09.041

Soutar, A. K., and Naoumova, R. P. (2007). Mechanisms of disease: genetic causes of familial hypercholesterolemia. Nat. Clin. Pract. Cardiovasc. Med. 4, 214-225. doi: $10.1038 /$ ncpcardio0836

Steinberg, D. (2004). Thematic review series: the pathogenesis of atherosclerosis. an interpretive history of the cholesterol controversy: part I. J. Lipid Res. 45, 1583-1593. doi: 10.1194/jlr.R400003-JLR200

Sui, T., Lau, Y. S., Liu, D., Liu, T., Xu, L., Gao, Y., et al. (2018b). A novel rabbit model of Duchenne muscular dystrophy generated by CRISPR/Cas9. Dis. Model. Mech. 11:dmm032201. doi: 10.1242/dmm.032201

Sui, T., Xu, L., Lau, Y. S., Liu, D., Liu, T., Gao, Y., et al. (2018a). Development of muscular dystrophy in a CRISPR-engineered mutant rabbit model with frame-disrupting ANO5 mutations. Cell Death Dis. 9:609. doi: 10.1038/s41419-018-0674-y

Sun, H., Unoki, H., Wang, X., Liang, J., Ichikawa, T., Arai, Y., et al. (2002b). Lipoprotein(a) enhances advanced atherosclerosis and vascular calcification in WHHL transgenic rabbits expressing human apolipoprotein(a). J. Biol. Chem. 277, 47486-47492. doi: 10.1074/jbc.M205814200

Sun, H., Usui, S., Shiomi, M., Watanabe, T., and Fan, J. (2002a). A rapid PCR method of genotyping LDL receptor mutations in WHHL rabbits. J. Atheroscler. Thromb. 9, 145-148. doi: 10.5551/jat.9.145

Suzuki, T., Palmer, B. M., James, J., Wang, Y., Chen, Z., VanBuren, P., et al. (2009). Effects of cardiac myosin isoform variation on myofilament function and crossbridge kinetics in transgenic rabbits. Circ. Heart Fail. 2, 334-341. doi: 10.1161/CIRCHEARTFAILURE.108.802298

Tesson, L., Usal, C., Menoret, S., Leung, E., Niles, B. J., Remy, S., et al. (2011). Knockout rats generated by embryo microinjection of TALENs. Nat. Biotechnol. 29, 695-696. doi: 10.1038/nbt.1940

Vicente, J. S., and Viudes-de-Castro, M. P. (1996). A sucrose-DMSO extender for freezing rabbit semen. Reproduct. Nutrit. Dev. 36, 485-492. doi: 10.1051/rnd:19960504

Wang, C., Nishijima, K., Kitajima, S., Niimi, M., Yan, H., Chen, Y., et al. (2017). Increased hepatic expression of endothelial lipase inhibits cholesterol diet-induced hypercholesterolemia and atherosclerosis in transgenic rabbits. Arterioscler. Thromb. Vasc. Biol. 37, 1282-1289. doi: 10.1161/ATVBAHA.117.309139

Wang, H. J., Lin, A. X., and Chen, Y. F. (2003). Association of rabbit sperm cells with exogenous DNA. Anim. Biotechnol. 14, 155-165. doi: $10.1081 / \mathrm{ABIO}-120026485$
Wang, Y., Niimi, M., Nishijima, K., Waqar, A. B., Yu, Y., Koike, T., et al. (2013). Human apolipoprotein A-II protects against diet-induced atherosclerosis in transgenic rabbits. Arterioscler. Thromb. Vasc. Biol. 33, 224-231. doi: 10.1161/ATVBAHA.112.300445

Wang, Z., Zhang, J., Li, H., Li, J., Niimi, M., Ding, G., et al. (2016). Hyperlipidemiaassociated gene variations and expression patterns revealed by wholegenome and transcriptome sequencing of rabbit models. Sci. Rep. 6:26942. doi: $10.1038 /$ srep 26942

Watanabe, Y. (1980). Serial inbreeding of rabbits with hereditary hyperlipidemia (WHHL-rabbit). Atherosclerosis 36, 261-268. doi: 10.1016/0021-9150(80)90234-8

Watanabe, Y., Ito, T., and Shiomi, M. (1985). The effect of selective breeding on the development of coronary atherosclerosis in whhl rabbits - an animal-model for familial hypercholesterolemia. Atherosclerosis 56, 71-79. doi: 10.1016/0021-9150(85)90085-1

Wu, H., Liu, Q., Shi, H., Xie, J., Zhang, Q., Ouyang, Z., et al. (2018). Engineering CRISPR/Cpf1 with tRNA promotes genome editing capability in mammalian systems. Cell. Mol. Life Sci. 75, 3593-3607. doi: 10.1007/s00018-018-2810-3

Xiao, N., Li, H., Shafique, L., Zhao, S., Su, X., Zhang, Y., et al. (2019). A novel paleyellow coat color of rabbits generated viaMC1R mutation with CRISPR/Cas9 system. Front. Genet. 10:875. doi: 10.3389/fgene.2019.00875

Yamada, S., Wang, K. Y., Tanimoto, A., Fan, J., Shimajiri, S., Kitajima, S., et al. (2008). Matrix metalloproteinase 12 accelerates the initiation of atherosclerosis and stimulates the progression of fatty streaks to fibrous plaques in transgenic rabbits. Am. J. Pathol. 172, 1419-1429. doi: 10.2353/ajpath.2008.070604

Yamamoto, T., Bishop, R. W., Brown, M. S., Goldstein, J. L., and Russell, D. W. (1986). Deletion in cysteine-rich region of Ldl receptor impedes transport to cell-surface in whhl rabbit. Science 232, 1230-1237. doi: 10.1126/science.3010466

Yamanaka, S., Balestra, M. E., Ferrell, L. D., Fan, J., Arnold, K. S., Taylor, S., et al. (1995). Apolipoprotein B mRNA-editing protein induces hepatocellular carcinoma and dysplasia in transgenic animals. Proc. Natl. Acad. Sci. U.S.A. 92, 8483-8487. doi: 10.1073/pnas.92.18.8483

Yan, H., Niimi, M., Matsuhisa, F., Zhou, H., Kitajima, S., Chen, Y., et al. (2020a). Apolipoprotein CIII deficiency protects against atherosclerosis in knockout rabbits. Arterioscler. Thromb. Vasc. Biol. 40, 2095-2107. doi: 10.1161/ATVBAHA.120.314368

Yan, H., Niimi, M., Wang, C., Chen, Y., Zhou, H., Matsuhisa, F., et al. (2020b). Endothelial lipase exerts its anti-atherogenic effect through increased catabolism of $\beta$-VLDLs. J. Atheroscler Thromb. 28, 157-168. doi: $10.5551 /$ jat. 55244

Yang, D., Song, J., Zhang, J., Xu, J., Zhu, T., Wang, Z., et al. (2016). Identification and characterization of rabbit ROSA26 for gene knock-in and stable reporter gene expression. Sci. Rep. 6:25161. doi: 10.1038/srep25161

Yang, D., Xu, J., and Chen, Y. E. (2019). Generation of rabbit models by gene editing nucleases. Methods Mol. Biol. 1874, 327-345. doi: 10.1007/978-1-4939-8831-0_19

Yang, D., Xu, J., Zhu, T., Fan, J., Lai, L., Zhang, J., et al. (2014). Effective gene targeting in rabbits using RNA-guided Cas9 nucleases. J. Mol. Cell Biol. 6, 97-99. doi: 10.1093/jmcb/mjt047

Yang, D., Zhang, J., Xu, J., Zhu, T., Fan, Y., Fan, J., et al. (2013). Production of apolipoprotein C-III knockout rabbits using zinc finger nucleases. J. Vis. Exp. 2013:50957. doi: 10.3791/50957

Yuan, L., Sui, T., Chen, M., Deng, J., Huang, Y., Zeng, J., et al. (2016). CRISPR/Cas9-mediated GJA8 knockout in rabbits recapitulates human congenital cataracts. Sci. Rep. 6:22024. doi: 10.1038/srep22024

Yuan, L., Yao, H., Xu, Y., Chen, M., Deng, J., Song, Y., et al. (2017). CRISPR/Cas9-mediated mutation of $\alpha \mathrm{A}$-crystallin gene induces congenital cataracts in rabbits. Invest. Ophthalmol. Visual Sci. 58, BIO34-BIO41. doi: 10.1167/iovs.16-21287

Zhang, J., Niimi, M., Yang, D., Liang, J., Xu, J., Kimura, T., et al. (2017). Deficiency of cholesteryl ester transfer protein protects against atherosclerosis in rabbits. Arterioscler. Thromb. Vasc. Biol. 37, 1068-1075. doi: 10.1161/ATVBAHA.117.309114

Zhang, S., Lu, F., Liu, Q., Liu, Y., Guan, X., Wei, Y., et al. (2016). Efficient generation of sFat-1 transgenic rabbits rich in $\mathrm{n}-3$ polyunsaturated fatty acids by intracytoplasmic sperm injection. Reprod. Fertil. Dev. 28, 310-318. doi: $10.1071 /$ RD13413 
Zhang, S. H., Reddick, R. L., Piedrahita, J. A., and Maeda, N. (1992). Spontaneous hypercholesterolemia and arterial lesions in mice lacking apolipoprotein E. Science 258, 468-471. doi: 10.1126/science.1411543

Zhao, S., Li, Y., Gao, S., Wang, X., Sun, L., Cheng, D., et al. (2015). Autocrine human urotensin ii enhances macrophage-derived foam cell formation in transgenic rabbits. Biomed Res. Int. 2015:843959. doi: 10.1155/2015/8 43959

Zhou, L., Xiao, Q., Bi, J., Wang, Z., and Li, Y. (2018). RabGTD: a comprehensive database of rabbit genome and transcriptome. Database. 2018:bay075. doi: 10.1093/database/bay075
Conflict of Interest: The authors declare that the research was conducted in the absence of any commercial or financial relationships that could be construed as a potential conflict of interest.

Copyright (c) 2021 Fan, Wang and Chen. This is an open-access article distributed under the terms of the Creative Commons Attribution License (CC BY). The use, distribution or reproduction in other forums is permitted, provided the original author(s) and the copyright owner(s) are credited and that the original publication in this journal is cited, in accordance with accepted academic practice. No use, distribution or reproduction is permitted which does not comply with these terms. 